\title{
Functional outcome of very preterm-born and small-for-gestational-age children at school age
}

\author{
Jozien C. Tanis', Meike H. van der Ree', Elise Roze', Anna E. Huis in 't Veld', Paul P. van den Berg'², Koenraad N.J.A. Van Braeckel' \\ and Arend F. Bos ${ }^{1}$
}

BACKGROUND: Our aim was to determine functional outcome of very preterm-born and small-for-gestational-age (SGA) children as compared with matched controls at school age.

METHODS: We included 28 very preterm SGA children (GA $<32$ wk, birth weight (BW) <10th percentile), born in 20002001. We also included 28 very preterm but appropriate-forgestational-age (AGA) children, matched for GA, gender, and birth year, as controls. We assessed motor skills, intelligence quotient (IQ), attention, verbal memory, visual perception, visuomotor integration, executive functioning, and behavior of both sets of children at school age.

RESULTS: The SGA children had a median GA of 29.7 wk and BW of $888 \mathrm{~g}$, whereas the controls had a median GA of $29.4 \mathrm{wk}$ and BW of 1,163 g. At $8.6 \mathrm{y}$, the median total IQ of the SGA children was 94 as compared with 95 in the controls (not significant). Performance IQ was significantly lower in SGA children (89 vs. $95, P=0.043)$, whereas verbal IQ was not (95 vs. 95). Total motor skills $(P=0.048)$ and fine motor skills $(P=0.021)$ were worse in SGA children. Furthermore, SGA children scored lower on selective attention $(P=0.026)$ and visual perception $(P=0.025)$. Other scores did not differ significantly between groups.

CONCLUSION: The differences we found between the groups were small. This suggests that the impaired functioning of very preterm-born SGA children is attributable to their having been born very preterm rather than to being SGA.

t has been shown that children who are born very preterm ( $<32 \mathrm{wk}$ of gestation) are at increased risk of impaired neurodevelopmental outcome (1-4). In addition, it has been shown that children born small-for-gestational age (SGA) are also at risk for poor neurodevelopmental outcome $(5,6)$. This holds good for SGA children born at term and also for those born preterm $(<37 w k)$ (5). Lower intelligence quotients (IQs) are reported in full-term and moderately preterm SGA children in particular $(7,8)$. It would be interesting to ascertain whether similar domains are affected in very preterm SGA children, given that the pathophysiologic mechanisms relating to brain development may be different in these infants. Studies on very preterm SGA children are scarce, and the findings are contradictory. Some studies report lower IQ scores $(6,9,10)$ and more behavioral problems or attention deficits in these children (9) as compared with controls (6), whereas others have found no differences as regards behavioral problems and attention deficits $(6,10)$. Cognitive impairment was restricted to verbal IQ only (10). Several specific neuropsychologic functions such as motor skills, executive functioning, memory, visuomotor integration, and visual perception were not studied. Furthermore, these follow-up studies in very preterm SGA children were performed at a relatively young age, i.e., up to the age of 5 y. For determining functional outcome, however, neuropsychological tests performed at school age are more reliable (1). At school age, functional demands are higher than at preschool age. In addition, from $\sim 6 \mathrm{y}$ of age onward, a larger variety of tests are available for assessing various motor, cognitive, and behavioral domains. Finally, because schoolchildren are used to tests at school, they are more compliant in test situations. Therefore, testing functional outcome is likely to be both reliable and valid at school age.

As yet, knowledge on the functional outcomes in SGA children born very preterm is limited. We expect that their functional outcomes would be poorer than those of very preterm but appropriate-for-gestational-age (AGA) children $(6,9,10)$. The question is whether this poor functional outcome at school age can be attributed to preterm birth alone, or whether being born SGA poses additional risks. Our aim was therefore to assess the performance of very preterm-born and SGA children in various motor, cognitive, and behavioral domains and to compare their performances with those of very preterm-born AGA controls at school age.

\section{RESULTS}

In 2000 and 2001, a total of 275 very preterm children were admitted to the neonatal intensive are unit (NICU) at our hospital. Among this group, 56 children were SGA, 18 (32\%) of whom died in the neonatal period. Of the survivors, five children were excluded because of major chromosomal and congenital abnormalities (one child with XXY syndrome, one child with congenital upper airway obstruction requiring tracheotomy, and three children with cardiac defects, i.e., tetralogy of Fallot, truncus arteriosus, and atrium septal defect with a large left-to-right shunt). The other 33 children were eligible for 
follow-up. Of these, we were unable to trace three children, and the parents of two other children declined to participate. We therefore had 28 (85\%) children in the follow-up program.

As controls we included 28 very preterm-born AGA children free of congenital abnormalities admitted in 2000 and 2001 to our hospital's NICU.

\section{Patient Characteristics}

In Table 1, we present an overview of the patient demographics of the SGA case children and the AGA control children $(11,12)$. The five SGA children who did not participate in the study had similar GA and birth weight (BW) values (median $30.1 \mathrm{wk}, 930 \mathrm{~g}$, respectively) to those of the 28 SGA children we included. At follow-up at 2 y of age the neurologic findings were normal in all these five children. The parents of two children reported behavioral problems, and one child showed a language delay. The SGA children who died in the neonatal period had a median GA of $29.1 \mathrm{wk}, \mathrm{BW} 730 \mathrm{~g}$, and head circumference (HC) of $24.5 \mathrm{~cm}$.

The demographics of the children in the study did not differ between groups, apart from the fact that $100 \%$ of the SGA children were delivered by cesarean section as compared with $61 \%$ in the AGA group. The HC at birth was lower in the SGA group than in the AGA group. In 11 of the SGA children $(39 \%), z$ scores of HC were below -1.28 , i.e., below the 10th percentile, whereas 17 (61\%) had normal HC values. The Score for Neonatal Acute Physiology, second version (SNAP-II) scores of the SGA children also appeared to be slightly higher, indicating greater severity of illness; however, this difference fell just short of significance (Table 1). Retinopathy of prematurity (maximum stage II without plus disease) occurred in four children in the SGA group and in

Table 1. Patient demographics

\begin{tabular}{|c|c|c|c|}
\hline & SGA & Controls & $P$ value \\
\hline Number & 28 & 28 & \\
\hline Male/female & $19 / 9$ & $19 / 9$ & NS \\
\hline Birth weight in grams & $888(766-1,068)$ & $1,163(1,079-1,442)$ & $<0.001$ \\
\hline Birth weight $z$ score ${ }^{a}$ & $-1.53(-1.99$ to -1.38$)$ & $-0.57(-1.06$ to 0.11$)$ & $<0.001$ \\
\hline Head circumference at birth $z$ score $^{b}(28 / 27)$ & $-1.0(-1.4$ to -0.5$)$ & $-0.2(-0.7$ to 0.3$)$ & 0.001 \\
\hline SES & $2(2-3)$ & $2(1-2)$ & NS \\
\hline Low (class 1) & 6 & 9 & \\
\hline Middle (class 2) & 14 & 13 & \\
\hline High (class 3) & 8 & 6 & \\
\hline SNAP-II & $14.5(8-23.5)$ & $12(5-15.5)$ & 0.088 \\
\hline NBRS & $3(3-4)$ & $3(2-4)$ & NS \\
\hline \multicolumn{4}{|l|}{ Late-onset morbidity } \\
\hline Retinopathy of prematurity & 4 & 1 & NS \\
\hline Necrotizing enterocolitis & 1 & 2 & NS \\
\hline Spontaneous intestinal perforation & 2 & 1 & NS \\
\hline Bronchopulmonary dysplasia ${ }^{c}$ & 9 & 5 & NS \\
\hline Late-onset sepsis & 9 & 8 & NS \\
\hline \multicolumn{4}{|l|}{ Cerebral pathology } \\
\hline
\end{tabular}

Data are expressed as median (percentile 25 and 75 ) or as absolute numbers. NS: $P>0.1$.

GMH, germinal matrix hemorrhage; NBRS, Nursery Neurobiologic Risk Score; NS, not significant; PVE, periventricular echodensity; PVHI, periventricular hemorrhagic infarction; SES, socioeconomic status; SGA, small for gestational age; SNAP, Score for Neonatal Acute Physiology.

a Z score according to Kloosterman (11). ' Z z score according to Niklasson (12). ‘ Bronchopulmonary dysplasia was defined as oxygen dependency at 36 wk postmenstrual age. 
Table 2. Cognitive, motor, and behavioral outcomes in SGA children as compared with controls

\begin{tabular}{|c|c|c|c|}
\hline Outcome type & $\mathrm{SGA}, n=28$ & Controls, $n=28$ & $P$ value \\
\hline \multicolumn{4}{|l|}{ Cognitive outcome } \\
\hline Total intelligence ${ }^{a}$ & $94(85-101)$ & $95(90-103)$ & NS \\
\hline $\begin{array}{l}\text { Verbal } \\
\text { intelligence }\end{array}$ & $95(86-103)$ & $95(88-107)$ & NS \\
\hline $\begin{array}{l}\text { Performance } \\
\text { intelligence }^{\mathrm{a}}\end{array}$ & 89 (81-95) & $95(88-105)$ & 0.043 \\
\hline \multicolumn{4}{|c|}{ Attention $^{b}(n=27 / 28)$} \\
\hline $\begin{array}{l}\text { Selective } \\
\text { attention }\end{array}$ & $16(5-50)$ & $50(16-63)$ & 0.026 \\
\hline $\begin{array}{l}\text { Attentional } \\
\text { control }\end{array}$ & $25(9-63)$ & $16(6-63)$ & NS \\
\hline \multicolumn{4}{|c|}{ Verbal memory ${ }^{b}(n=27 / 28)$} \\
\hline $\begin{array}{l}\text { Immediate } \\
\text { recall }\end{array}$ & $38(8-61)$ & $44(9-70)$ & NS \\
\hline Delayed recall & $37(7-68)$ & $37(13-55)$ & NS \\
\hline $\begin{array}{l}\text { Visual perception }{ }^{b} \\
(n=26 / 26)\end{array}$ & $50(28-63)$ & $63(50-84)$ & 0.025 \\
\hline $\begin{array}{l}\text { Visuomotor } \\
\text { integration }^{b} \\
(n=27 / 28)\end{array}$ & $51(6-75)$ & $51(51-75)$ & NS \\
\hline $\begin{array}{l}\text { Executive } \\
\text { functioning }\end{array}$ & $44.5(29.3-85.0)$ & $37.5(16.3-76.0)$ & NS \\
\hline \multicolumn{4}{|l|}{ Motor outcome ${ }^{d}$} \\
\hline Total score & $11.0(7.9-17.9)$ & $9.8(5.0-14.5)$ & NS \\
\hline Total z score & $-1.5(-2.2$ to -1.2$)$ & $-1.2(-1.8$ to 0.4$)$ & 0.048 \\
\hline $\begin{array}{l}\text { Manual } \\
\text { dexterity }\end{array}$ & $6.3(3.1-9.0)$ & $3.3(1.0-6.5)$ & 0.021 \\
\hline Ball skills & $3.0(1.6-5.9)$ & $2.5(0.1-4.0)$ & NS \\
\hline $\begin{array}{l}\text { Static-dynamic } \\
\text { balance }\end{array}$ & $2.8(1.0-4.0)$ & $2.3(0.1-4.9)$ & NS \\
\hline \multicolumn{4}{|l|}{ Behavioral outcome ${ }^{d}$} \\
\hline $\begin{array}{l}\text { Total behavioral } \\
\text { problems }\end{array}$ & $31.5(17.3-51.8)$ & $29.5(10.3-48.5)$ & NS \\
\hline $\begin{array}{l}\text { Internalizing } \\
\text { problems }\end{array}$ & $7.5(4.0-11.0)$ & $6.0(1.0-12.5)$ & NS \\
\hline $\begin{array}{l}\text { Externalizing } \\
\text { problems }\end{array}$ & $5.0(1.3-10.5)$ & $6.5(1.0-14.5)$ & NS \\
\hline $\begin{array}{l}\text { Total ADHD score } \\
(n=28 / 27)\end{array}$ & $14.0(7.3-28.0)$ & $12.0(6.0-17.0)$ & NS \\
\hline $\begin{array}{l}\text { Attention } \\
\text { deficiency }\end{array}$ & $4.0(2.0-14.8)$ & $3.0(2.0-7.0)$ & NS \\
\hline Hyperactivity & $5.5(3.0-9.8)$ & $4.0(1.0-8.0)$ & NS \\
\hline Impulsiveness & $4.0(2.0-9.3)$ & $4.0(1.0-6.0)$ & NS \\
\hline
\end{tabular}

Data are given as median (percentile 25 and 75).

ADHD, attention-deficit hyperactivity disorder; NS, not significant; SGA, small for gestational age.

alntelligence quotients. ${ }^{b}$ Percentiles (low percentile means poor outcome). cPercentiles (high percentile means poor outcome). ${ }^{\text {dRaw scores. }}$

one child in the AGA control group. None of these children became blind.

The median age at follow-up for this study was $8.6 \mathrm{y}$ (interquartile range 8.3-9.1). By this time, the median $z$ scores of the $\mathrm{HC}$ according to age were -0.91 (interquartile range -1.55 to -0.24 ) in the SGA children, and -1.05 (interquartile range -1.60 to 0.29 ) in the AGA children (not significant).

None of the children developed cerebral palsy.

\section{Cognitive Outcome}

Of the 28 children included in the SGA case group, 24 (86\%) attended regular schools and $4(14 \%)$ received special education, 3 of them because of learning difficulties and 1 because of developmental coordination disorder. In addition, 9 (32\%) of the 28 children had had to repeat a class or classes in elementary school (starting at the age of $4 \mathrm{y}$ ) at least once. One child in the AGA control group received special education and all the others went to regular schools. Of the 28 control children, $9(32 \%)$ had had to repeat a class or classes. Neither the level of education nor the repeating of classes was significantly different between the two groups.

In Table 2, we present the median scores on cognitive tests. One child in the SGA group had difficulties with all cognitive tests because of very low intelligence, as seen by IQ scores (total IQ <55). In two SGA children and two AGA controls, the visual perception test was not administered reliably. In comparison to AGA controls, SGA children scored significantly lower on performance IQ, selective attention, and visual perception. Scores on total and verbal IQ, attentional control, verbal memory, visuomotor integration, and executive functioning did not differ significantly between the groups.

In Table 3, we classified the children's scores into the categories normal ( $>15$ th percentile), borderline (5th to 15 th percentiles), and abnormal ( $<5$ th percentile). The child whose neuropsychological functions could not be assessed because of very low intelligence was classified as "abnormal." Before adjustment, the odds ratios (ORs) for impaired outcome in the SGA group for borderline/abnormal vs. normal, were 4.33 (95\% confidence interval (CI), 0.81-23.10, $P=0.086$ ) for total IQ, 4.63 (95\% CI, 1.11-19.26, $P=0.035)$ for performance IQ, and 3.18 (95\% CI, 0.99-10.23, $P=0.053)$ for selective attention. The ORs for abnormal vs. borderline/normal were not significant. In Table 4, we present the ORs after adjustment for SNAP-II and socioeconomic status (SES). After these adjustments, the ORs were lower for total IQ and higher for performance IQ and selective attention.

The data shown in Tables 3 and 4 confirm the analyses of the median scores as shown in Table 2, except with respect to visual perception. Total intelligence was significantly lower in the SGA group but only after we categorized outcomes in this domain.

\section{Motor Outcome}

We were able to assess the motor skills of all the children, using the Movement Assessment Battery for Children (Movement $\mathrm{ABC}$ ). Manual dexterity was significantly more impaired in SGA children (Table 2). The total scores per the Movement $\mathrm{ABC}$ were also higher (i.e., poorer) and reached significance when we transformed them into $z$ scores. Moreover, a greater proportion of the children in the SGA group were classified as 
Table 3. Cognitive, motor, and behavioral outcomes in SGA children as compared with controls, classified as normal, borderline, or abnormal

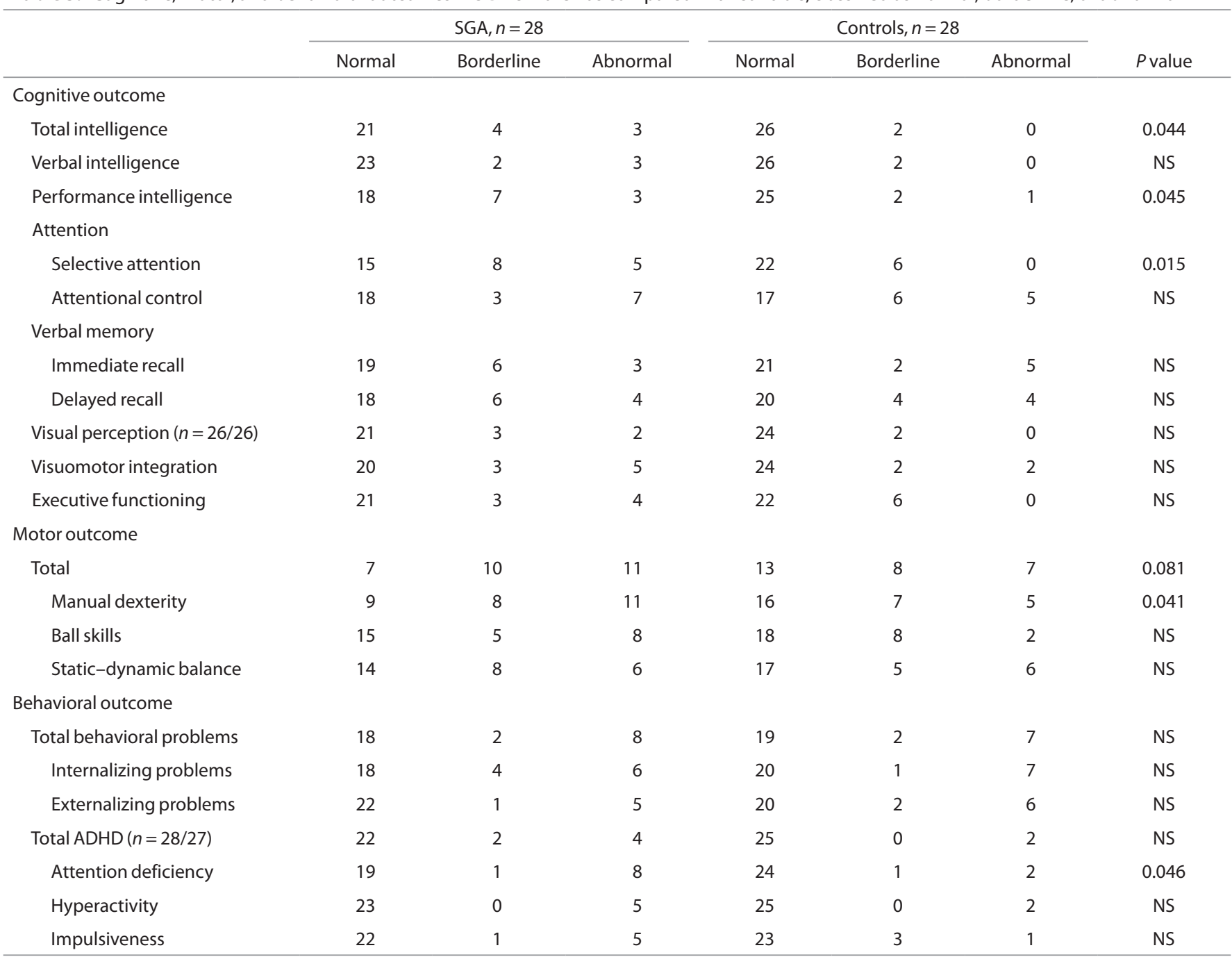

Data are given as absolute numbers. Normal was defined as $>15$ th percentile, borderline as 5 th to 15 th percentile, and abnormal as $<5$ th percentile. With regard to intelligence, normal was defined as $I Q>85$, borderline as $I Q 70-85$, and abnormal as $I Q<70$. NS: $P>0.1$.

ADHD, attention-deficit hyperactivity disorder; NS, not significant; SGA, small for gestational age.

borderline or abnormal for total scores in Movement $\mathrm{ABC}$ as well as for manual dexterity (Table 3). Before adjustment, the ORs for impaired outcome in children in the SGA group for borderline/abnormal vs. normal were 2.60 (95\% CI, 0.84-8.07, $P=0.098$ ) for total motor scores and 2.82 (95\% CI, 0.95-8.38, $P=0.063)$ for manual dexterity. For abnormal vs. normal/ borderline, the ORs were 2.98 (95\% CI, $0.87-10.17, P=0.082$ ) for manual dexterity and 5.20 (95\% CI, $0.99-27.23, P=0.051)$ for ball skills. After adjustment for SNAP-II and SES, the ORs were lower for manual dexterity (abnormal vs. normal/ borderline), higher for total motor outcome, and unchanged for manual dexterity (borderline/abnormal vs. normal) as well as for ball skills (abnormal vs. normal/borderline) (Table 4).

\section{Behavioral Outcome}

The parents of all the children filled out details in the Child Behavior Check List (CBCL). For one child in the AGA control group, the results of the attention-deficit hyperactivity disorder (ADHD) questionnaire were lacking because it had not been filled out completely. Median scores were not significantly different between the groups (Table 2). When the children were classified as normal, borderline, or abnormal, we found that more SGA children had attention deficits (Table 3). Before adjustment, the ORs for attention deficits in the SGA children were 3.79 (95\% CI, 0.90-15.97, $P=0.070$ ) when classified as borderline/abnormal vs. normal, and 5.00 (95\% CI, $0.95-26.23, P=0.057)$ when classified as abnormal vs. nor$\mathrm{mal} /$ borderline. The adjusted ORs were slightly higher, thereby confirming these findings (Table 4).

\section{Relation Between Functional Outcome, Head Size at Birth, and at Follow-Up}

Within the group of SGA children, the $z$ scores for HC at birth did not correlate with any of the outcome measures, apart from the subscale "Impulsiveness" in the Dutch ADHD questionnaire. Lower $z$ scores of $\mathrm{HC}$ correlated with higher scores on 
Table 4. Adjusted odds ratios for impaired outcome in SGA children as compared with controls

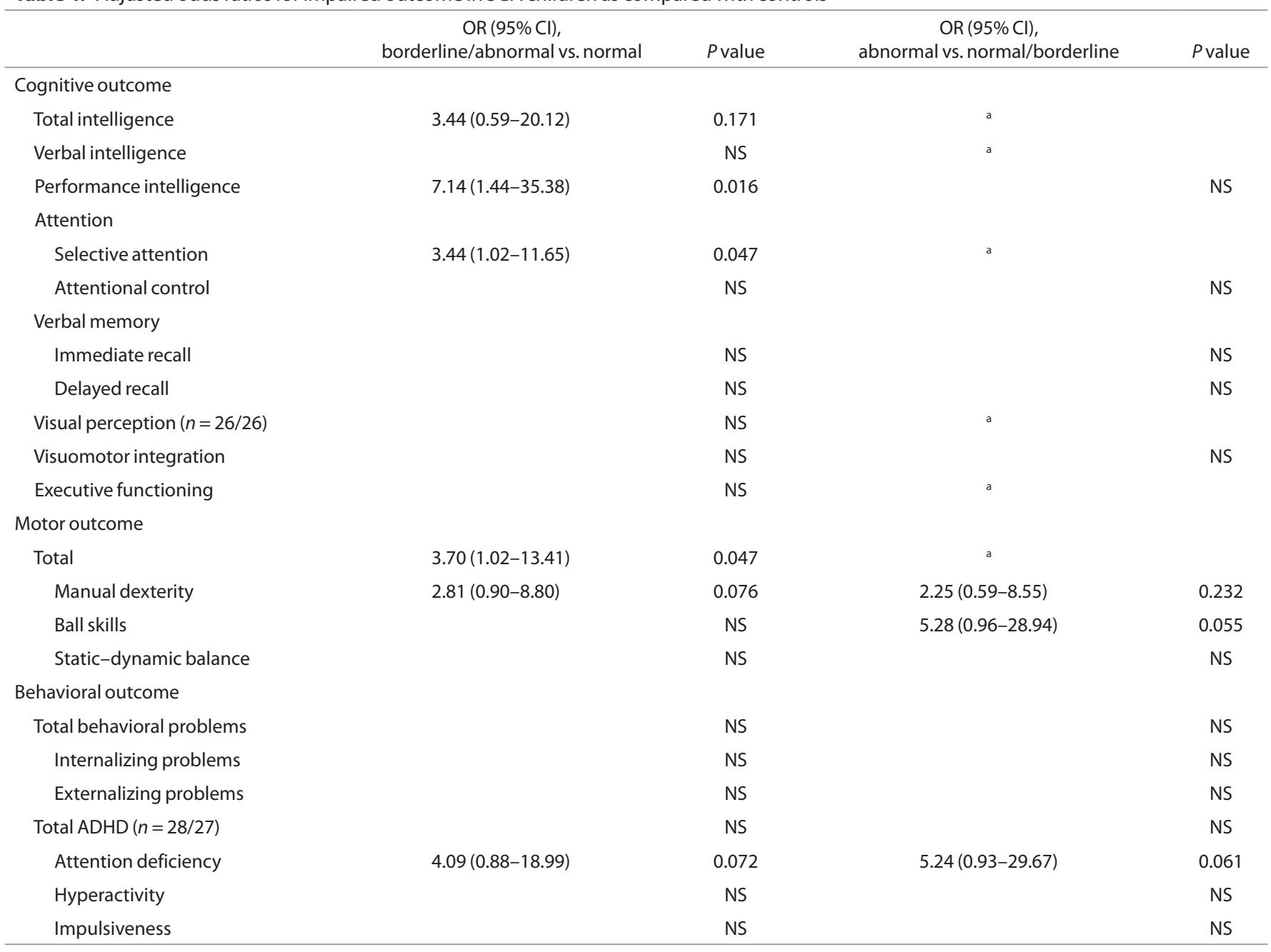

Adjusted for SES and SNAP-II. NS: $P>0.1$.

Cl, confidence interval; NS, not significant; OR, odds ratio; SES, socioeconomic status; SGA, small for gestational age; SNAP, Score for Neonatal Acute Physiology.

a Not possible to calculate due to empty fields.

impulsiveness (Spearman's $r=-0.501, P=0.007$ ). No differences existed between SGA children with brain sparing and those without.

The $z$ scores of the HC in children in the SGA group at follow-up correlated with motor skills and behavior per the CBCL but not with scores on the cognitive tests. Lower $z$ scores for HC correlated with poorer scores on total motor skills, in particular static and dynamic balance (Spearman's $r=-0.415, P=0.039$ and $r=-0.517, P=0.008$, respectively). Manual dexterity and ball skills did not correlate with head size at follow-up. As regards behavior, the lower $z$ scores for $\mathrm{HC}$ correlated with poorer scores on total behavioral problems $(r=-0.520, P=0.008)$, externalizing problems $(r=-0.410, P=$ $0.042)$, and internalizing problems $(r=-0.501, P=0.011)$.

\section{DISCUSSION}

The aim of our study was to assess, at school age, the performance levels in various motor, cognitive, and behavioral domains in children who had been born very preterm and
SGA, and to compare these performance levels with those of children who had also been born very preterm but with body weights AGA. We found that the SGA children performed less well on performance intelligence, selective attention, visual perception, and motor skills (particularly fine motor skills) as compared with the very preterm AGA group. We found no significant differences as regards total and verbal intelligence, gross motor skills (balance and ball skills), verbal memory, visuomotor integration, executive functioning, or behavior.

With regard to IQ, the differences between the SGA children and the controls were small. Total IQ and verbal IQ did not differ between the groups, and only performance IQ was $\sim 0.5$ SD lower in the SGA group. Contrary to some other studies that had reported lower total IQ in SGA children $(6,9)$, our findings suggest that being born preterm affects IQ more than does growth restriction. This is more so in verbal IQ than in performance IQ (10). A large population-based cohort study reported follow-up data of the EPIPAGE cohort at $5 \mathrm{y}$ of age (6). Their inclusion rate for the cognitive tests was only 


\section{Articles | Tanisetal.}

$\sim 65 \%$. This may have caused bias in the results. Of note, in the EPIPAGE cohort, lower IQs were found in SGA children with GA 29-32 wk, whereas there was no such finding in SGA children with GA $24-28 \mathrm{wk}$. Two other studies that found a poorer total and verbal IQ in SGA children included approximately the same number of children as our study did $(9,10)$. One of these studies was performed in children $3 \mathrm{y}$ of age (9) and the other in children 5 y of age (10). In our study, the children were tested between the ages of 7 and $10 \mathrm{y}$. By implication, this may mean that, as they grow older, very preterm SGA children catch up on intelligence lag but not on performance IQ.

As compared with the controls, the SGA children in our study also obtained lower scores on selective attention and visual perception. These findings confirm the data from other follow-up studies of very preterm SGA children (5-7,9). Apparently, attention is a vulnerable neuropsychological domain in very preterm SGA children. Attention is also very often affected in SGA children born moderately preterm or at full term $(5,7)$. Earlier, lower scores on visual perception were found in fullterm and moderately preterm SGA children (7).

In our study, we found that fine motor skills in particular were slightly more affected in the very preterm SGA children. In a study that used a standard neurologic examination, Guellec et al. could not demonstrate differences in motor outcome between very preterm SGA cases and AGA controls assessed at the age of 5 y (6). Conflicting results on outcome as regards motor skills have been reported in preterm SGA children when the definition of prematurity is extended to $37 \mathrm{wk}$ GA (5). Padilla et al. found no differences between SGA cases and AGA controls with respect to either gross or fine motor skills (13). By contrast, Matilainen et al. reported that both gross and fine motor skills were more impaired in SGA children (14). Other studies have also reported increased incidences of spastic motor outcomes and gross motor impairment $(15,16)$. Of note, in our study motor skills were observed to be affected in as many as $\sim 50 \%$ of the children in both the SGA and AGA groups. This suggests that GA rather than growth restriction is the major determinant of the risk of developing impairment in fine motor skills (6).

With regard to behavioral problems, we did not find any significant differences between the two groups of very preterm children. An earlier study had reported more behavioral problems in very preterm SGA children (17), whereas other studies failed to confirm these findings $(6,18)$. As regards ADHD, we found no significant difference between the SGA children and the controls. This is in line with the results of previous studies $(6,10)$. A higher incidence of behavioral problems and ADHD is consistently found in preterm children as compared with children born at term $(1,3,19)$, and this was confirmed in our study.

We did not find the outcomes to be worse in the SGA children as compared with the AGA controls in such cognitive domains as verbal memory, verbal IQ, and executive functioning. Furthermore, the percentage of children who repeated classes in school was similar in the two groups. Cognitive skills have very rarely been assessed in children born very preterm and SGA; most studies reporting in the domains of cognitive skills studied SGA children born up to $37 \mathrm{wk}$ GA or those born full term. The studies reported poorer performances by these children with respect to these neuropsychological domains $(7,8,14,20)$. In our study, the rates of abnormal and borderline scores in nearly all domains exceeded those one would expect in a normal population.

Although children born very preterm and SGA have poorer cognitive and fine motor outcomes, the differences in outcomes as compared with the matched controls (children born very preterm but AGA) were small, and behavior did not seem to be different between the two groups. Very preterm birth in itself is associated with poor IQ, poor motor skills $(1,2,4)$, and behavioral problems (19). Apparently, intrauterine growth restriction (IUGR) does not contribute much to making outcomes worse. We offer two explanations for this finding. First, our study group consisted of children born very preterm and SGA. Given their lower BW, SGA infants have a higher mortality rate than AGA infants do $(6,21)$. Therefore very preterm SGA children who do survive may have been less growth restricted than SGA children born at full term. Second, in our group, IUGR occurred rather early in pregnancy, as was reflected by the high percentage of children with $\mathrm{HC}$ values lower than the 10th percentile. If growth restriction had occurred later in pregnancy, it could have led to other patterns of brain injury. We speculate that these two factors partly explain some of the smaller differences in outcome measures between SGA cases and AGA controls.

Several causes may lead to an infant being born SGA. Some of these are congenital or chromosomal abnormalities, pathology of the placenta (with IUGR as a consequence), and being constitutionally small because of the short stature of the parents. In our study, we excluded the first of these possible causes, and therefore the study group consisted of those who had experienced IUGR and those who were constitutionally small. Both these factors might slightly delay or alter brain development in utero, and therefore small differences in functional outcome may be seen between very preterm-born SGA children and very preterm-born AGA children.

Nevertheless, in several neuropsychological domains the outcomes we found in the SGA children were definitely poorer than in the AGA controls. The most striking findings were lower levels of performance IQ, selective attention, and fine motor skills. We considered several potential explanations for our findings. The clinical characteristics did not differ between the groups, apart from higher SNAP-II scores in the SGA group; indeed, the results remained similar after adjustment for SNAP-II scores. There was also a significant difference in cesarean section rates between the two groups, being higher in the SGA group. This suggests that the SGA children experienced significantly greater distress in utero than the controls did, possibly contributing to the observed differences in outcomes. However, Apgar and neurobiologic risk scores did not differ between the groups. Within the SGA case group, we could not demonstrate an association between IQ and small HC, either at birth or at follow-up. This was in contrast to the findings reported by Geva et al., who studied neuropsychological outcomes of mainly full-term growthrestricted children (7). However, small head size at follow-up appeared to have some association with behavioral problems and impaired motor skills. Possibly decrease in neural connectivity 
and in the complexity of the neural networks played a role in the differences we found between very preterm SGA and AGA children, but this is highly speculative.

To the best of our knowledge, this is one of the few studies that reports functional outcome at school age of various developmental domains in very preterm-born SGA children. The strength of our study is that a large array of neuropsychological domains, relevant for everyday functioning, was tested. We took great care in selecting an appropriate control group. Controls were matched for GA, gender, and birth year.

We also recognize some limitations of our study. This was a single-center study, and this may limit the generalizability of our results. We reported on only a small group of very preterm SGA children. Executive functioning was assessed only by means of a questionnaire. We used the parent's occupation as an indicator of SES instead of (for example) education. Nevertheless, we believe that the findings in our cohort represent the functional skills and disabilities in very preterm SGA children in general.

Our findings suggest that care should be taken to closely monitor preterm SGA children during follow-up, particularly in the domains of attention, performance IQ, and fine motor skills. Future research should focus on the pathophysiological process of brain development in IUGR, and on the prevention of these functional deficits.

\section{Conclusion}

Very preterm-born SGA children performed worse on performance intelligence, selective attention, visual perception, and motor skills (in particular, fine motor skills) as compared with matched AGA controls. The differences, however, were small. This suggests that the observed impairment in the functioning of very preterm-born SGA children is attributable to their very preterm birth per se rather than to being SGA. Our data also suggest that very preterm-born SGA children should be followed up and screened for fine motor and attention deficits at school age.

\section{METHODS}

\section{Patients}

This was a case-control study. As cases, we included children born very preterm $(<32 \mathrm{wk}$ GA) who were also SGA, defined as having a BW lower than the 10th percentile ( $z$ score -1.28$)$ of the Dutch Kloosterman growth charts (11). At birth, these children had been admitted to the NICU of the University Medical Center Groningen during the years 2000 and 2001. We found these case children by searching the patient database on the basis of the diagnoses "SGA" and "IUGR." Those with chromosomal and congenital abnormalities were excluded. As controls, we included very preterm-born children (matched for age and gender with the case children) who had also been admitted to the same NICU during the same period, with birth times closest (either before or after) to each SGA case but with BWs that were AGA. Clinical characteristics such as Apgar scores and HC at birth were collected from the medical files. The study was approved by the Medical Ethics Committee of the University Medical Center Groningen.

\section{Testing Procedure}

This was a hypothesis-generating study. Therefore, tests on multiple domains were performed.

All the parents gave their written informed consent to participate in the follow-up program.

Follow-up consisted of a battery of tests that took $\sim 2.5 \mathrm{~h}$ to complete, including breaks. The tester was blinded as to the diagnosis of SGA in the children. During these visits we also measured the children's HC, which we transformed into $z$ scores. During testing, the child was in a separate room with the tester, while one or both of the parents were filling out questionnaires in another room. Test scores generated when a child was too tired and/or uncooperative (as assessed by the trained tester) were excluded, as were those accompanied by incomplete questionnaires.

\section{Cognitive Measures}

Before testing the children, we first determined whether the children attended regular school or received special education, and whether they had repeated classes at any time. Cognitive outcome was assessed using several standardized tests.

A short form of the Wechsler Intelligence Scale for Children, 3rd edition, Dutch version, was used to determine intelligence $(22,23)$. We calculated total IQ on the basis of the verbal IQ and performance IQ subtests.

Selective attention and attentional control were measured using two subtests, "Map Mission" and "Opposite Worlds," of the Test of Everyday Attention for Children (24).

We assessed verbal memory using the Rey Auditory Verbal Learning Test (25). This test consists of a 15-word list that is repeated to the child five times. After each trial we tested immediate recall. Delayed recall was assessed after an interval of $20 \mathrm{~min}$.

For assessing visual perception and visuomotor integration, we used two subtests, "Geometric Puzzles" and "Design Copying," of the Neuropsychological Assessment, 2nd edition (26).

Executive functioning in daily life was assessed using the Behavior Rating Inventory of Executive Function questionnaire (27), which was filled out by the parents.

\section{Motor Measures}

Motor outcome was assessed using the Movement ABC (28). This is a standardized test that measures total motor performance based on subscores for manual dexterity (fine motor skills), ball skills, and static-dynamic balance (coordination). The higher the score, the poorer the outcome.

\section{Behavioral Measures}

We used two questionnaires to assess the children's behavior. Emotional and behavioral problems were assessed using the CBCL (29).

Symptoms of ADHD were assessed using the Dutch ADHD questionnaire (30).

\section{Potential Confounders}

To estimate the degree of illness experienced by the children during the neonatal period, we used two scoring systems. These were the Nursery Neurobiologic Risk Score (31) and the SNAP-II (32). The Neurobiologic Risk Score estimates the degree of illness during the entire period of admission and is based on $\mathrm{pH}$ value, the need for mechanical ventilation, and the presence of brain white matter abnormalities, infections, convulsions, cerebral hemorrhages, and hypoglycemia. The SNAP-II assesses severity of illness on the first day of life. It is based on blood pressure, lowest temperature, $\mathrm{PO}_{2} / \mathrm{FiO}_{2}$ (fraction of inspired oxygen) ratio, lowest serum $\mathrm{pH}$, the presence of multiple seizures, and urine output during the first $24 \mathrm{~h}$.

We also considered SES as a possible confounder. SES was determined using a classification of occupations developed in The Netherlands (33). We categorized SES into three classes based on the parents' occupations, taking the higher of the occupation levels of the two parents of each child. Class 1 corresponds with the lower-level occupations, class 3 with higher-level occupations.

\section{Statistical Analysis}

SPSS 16.0 software for Windows was used for all data analyses. IQ scores were calculated on the basis of the mean scores on the verbal and performance subtests of the Wechsler Intelligence Scale for Children. We used norm scores from the manuals for cognitive outcome (Test of Everyday Attention for Children, Auditory Verbal Learning Test, Neuropsychological Assessment), motor outcome (Movement ABC), and the questionnaires (ADHD questionnaire, CBCL, Behavior Rating Inventory of Executive Function). Percentiles on the standardization 
samples of the Movement $\mathrm{ABC}$ and each cognitive test were used to classify scores into normal ( $>15$ th percentile), borderline (5th to 15 th percentile), and abnormal ( $<5$ th percentile). We used a similar classification for the CBCL, Behavior Rating Inventory of Executive Function, and $\mathrm{ADHD}$ questionnaires, on the basis of the criteria set out in the manuals. We transformed the raw total motor scores of the Movement $\mathrm{ABC}$ into percentiles and subsequently into $z$ scores, in accordance with the instructions in the manual. We did so to do justice to the variability in the motor skills of the group of children below the 1st percentile who, while showing a wide range of raw total motor scores, could not be differentiated on the basis of the percentiles. Where appropriate, we used the Mann-Whitney U-test, Fisher's exact test, and $\chi^{2}$ test for trend to test for differences between the case and control groups, both for outcome measures and for potential confounders. We used Spearman's rank correlation to test the correlation between clinical characteristics (e.g., HC $z$ scores at birth) and confounders on the one hand, and cognitive, motor, and behavioral outcome scores on the other. We also tested whether SGA children with brain sparing (defined as $\mathrm{HC} z$ scores BW $z$ scores $>0.75$ SD) had different outcomes as compared to SGA children without brain sparing. Throughout the analyses, $P<0.05$ (twotailed) was considered to be statistically significant.

We used univariate logistic regression analyses to calculate ORs for abnormal outcomes according to group. We did so twice: first we took borderline and abnormal outcomes together vs. normal outcome, and next we took abnormal outcome vs. normal and borderline outcomes. We then performed multivariate logistic regression analyses. In the multivariate model, we included the potential confounders that were associated with group allocation or outcome measures at $P \leq 0.1$. SES was also included in the multivariate model. We decided to report all ORs with $P \leq 0.1$, both in the univariate and in the multivariate models.

\section{STATEMENT OF FINANCIAL SUPPORT}

No financial assistance has been received in support of this study.

\section{ACKNOWLEDGMENTS}

This study was part of the research program of the Research School for Behavioral and Cognitive Neurosciences, University of Groningen, The Netherlands. We greatly appreciate the help of Titia Brantsma-van Wulfften Palthe in correcting the English manuscript.

\section{REFERENCES}

1. Johnson S. Cognitive and behavioural outcomes following very preterm birth. Semin Fetal Neonatal Med 2007;12:363-73.

2. Fawke J. Neurological outcomes following preterm birth. Semin Fetal Neonatal Med 2007;12:374-82.

3. Bhutta AT, Cleves MA, Casey PH, Cradock MM, Anand KJ. Cognitive and behavioral outcomes of school-aged children who were born preterm: a meta-analysis. JAMA 2002;288:728-37.

4. Aarnoudse-Moens CS, Weisglas-Kuperus N, van Goudoever JB, Oosterlaan J. Meta-analysis of neurobehavioral outcomes in very preterm and/or very low birth weight children. Pediatrics 2009;124:717-28.

5. Bos AF, Einspieler C, Prechtl HF. Intrauterine growth retardation, general movements, and neurodevelopmental outcome: a review. Dev Med Child Neurol 2001;43:61-8.

6. Guellec I, Lapillonne A, Renolleau S, et al.; Neurologic outcomes at school age in very preterm infants born with severe or mild growth restriction. Pediatrics 2011;127:e883-91.

7. Geva R, Eshel R, Leitner Y, Valevski AF, Harel S. Neuropsychological outcome of children with intrauterine growth restriction: a 9-year prospective study. Pediatrics 2006;118:91-100.

8. Leitner Y, Fattal-Valevski A, Geva R, et al. Neurodevelopmental outcome of children with intrauterine growth retardation: a longitudinal, 10-year prospective study. J Child Neurol 2007;22:580-7.

9. Sung IK, Vohr B, Oh W. Growth and neurodevelopmental outcome of very low birth weight infants with intrauterine growth retardation: comparison with control subjects matched by birth weight and gestational age. J Pediatr 1993;123:618-24.

10. Morsing E, Asard M, Ley D, Stjernqvist K, Marsál K. Cognitive function after intrauterine growth restriction and very preterm birth. Pediatrics 2011;127:e874-82.
11. Kloosterman GJ. On intrauterine growth: the significance of prenatal care. Int J Gynaecol Obstet 1970;8:895-912.

12. Niklasson A, Albertsson-Wikland K. Continuous growth reference from 24th week of gestation to 24 months by gender. BMC Pediatr 2008;8:8.

13. Padilla N, Perapoch J, Carrascosa A, Acosta-Rojas R, Botet F, Gratacós E. Twelve-month neurodevelopmental outcome in preterm infants with and without intrauterine growth restriction. Acta Paediatr 2010;99:1498-503.

14. Matilainen R, Heinonen K, Siren-Tiusanen H, Jokela V, Launiala K. Neurodevelopmental screening of in utero growth-retarded prematurely born children before school age. Eur J Pediatr 1987;146:453-7.

15. Hadders-Algra M, Huisjes HJ, Touwen BC. Preterm or small-forgestational-age infants. Neurological and behavioural development at the age of 6 years. Eur J Pediatr 1988;147:460-7.

16. Claas MJ, Bruinse HW, Koopman C, van Haastert IC, Peelen LM, de Vries LS. Two-year neurodevelopmental outcome of preterm born children $\leq 750 \mathrm{~g}$ at birth. Arch Dis Child Fetal Neonatal Ed 2011;96:F169-77.

17. Zubrick SR, Kurinczuk JJ, McDermott BM, McKelvey RS, Silburn SR, Davies LC. Fetal growth and subsequent mental health problems in children aged 4 to 13 years. Dev Med Child Neurol 2000;42:14-20.

18. van den Broek AJ, Kok JH, Houtzager BA, Scherjon SA. Behavioural problems at the age of eleven years in preterm-born children with or without fetal brain sparing: a prospective cohort study. Early Hum Dev 2010;86:379-84.

19. Reijneveld SA, de Kleine MJ, van Baar AL, et al. Behavioural and emotional problems in very preterm and very low birthweight infants at age 5 years. Arch Dis Child Fetal Neonatal Ed 2006;91:F423-8.

20. Gutbrod T, Wolke D, Soehne B, Ohrt B, Riegel K. Effects of gestation and birth weight on the growth and development of very low birthweight small for gestational age infants: a matched group comparison. Arch Dis Child Fetal Neonatal Ed 2000;82:F208-14.

21. Regev RH, Lusky A, Dolfin T, Litmanovitz I, Arnon S, Reichman B. Excess mortality and morbidity among small-for-gestational-age premature infants: a population-based study. J Pediatr 2003;143:186-91.

22. Kort W, Compaan EL, Bleichrodt N, et al. WISC-IIINL: Wechsler Intelligence Scales for Children, 3rd edn, Dutch version. Amsterdam, The Netherlands: NIP Dienstencentrum, 2002.

23. Gregoire J. Comparison of three short forms of the Wechsler intelligence scale for children - third edition (WISC-III). Eur Rev Appl Psychol 2000;50:437-41.

24. Manly T, Anderson V, Nimmo-Smith I, Turner A, Watson P, Robertson IH. The differential assessment of children's attention: the Test of Everyday Attention for Children (TEA-Ch), normative sample and ADHD performance. J Child Psychol Psychiatry 2001;42:1065-81.

25. van den Burg W, Kingma A. Performance of 225 Dutch school children on Rey's Auditory Verbal Learning Test (AVLT): parallel test-retest reliabilities with an interval of 3 months and normative data. Arch Clin Neuropsychol 1999;14:545-59.

26. Korkman M, Kirk U, Kemp SL. NEPSY II: Clinical and Interpretative Manual. San Antonio, TX: PsychCorp, 2007.

27. Gioia GA, Isquith PK, Guy SC, Kenworthy L. Behavior rating inventory of executive function. Child Neuropsychol 2000;6:235-8.

28. Smits-Engelsman BCM. Movement Assessment Battery for Children. Lisse, The Netherlands: Swets \& Zeitlinger, 1998.

29. Achenbach TM, Edelbrock C. Manual for the Child Behavior Checklist: 4-8 and 1991 Profile. Burlington, Vermont: University of Vermont, Department of Psychiatry, 1991.

30. Scholte EM, van der Ploeg JD. [ADHD-questionnaire (AVL) manual]. Houten, The Netherlands: Bohn Stafleu Van Loghum, 2004.

31. Brazy JE, Eckerman CO, Oehler JM, Goldstein RF, O’Rand AM. Nursery Neurobiologic Risk Score: important factor in predicting outcome in very low birth weight infants. J Pediatr 1991;118:783-92.

32. Richardson DK, Corcoran JD, Escobar GJ, Lee SK. SNAP-II and SNAPPE-II: Simplified newborn illness severity and mortality risk scores. J Pediatr 2001;138:92-100.

33. Divisie Sociale en Ruimtelijke statistieken. Standard Classification OfOccupations 1992, edition 2001. Voorburg/Heerlen, The Netherlands: Centraal Bureau voor de Statistiek, 2001. 